\title{
Rinsing carbohydrate solutions in the mouth; effect on cycle time trial performance in the heat
}

\author{
P. Watson and D. Nichols \\ School of Sport, Exercise and Health Sciences, Loughborough University, Leicestershire, LE11 $3 T U$
}

The ingestion of exogenous carbohydrate (CHO) has been demonstrated to enhance exercise performance in both temperate and warm environments $^{(1)}$. While there is a clear metabolic rationale for this response when exercise is undertaken in cool conditions, CHO availability is not limiting during exercise in the heat. In addition to the well-defined peripheral effects, it has been speculated that the presence of $\mathrm{CHO}$ in the oral cavity may result in the activation of receptors that prime the body for the incoming delivery of $\mathrm{CHO}$. In fact, rinsing a $\mathrm{CHO}$ solution in the mouth has been demonstrated to improve exercise performance in temperate conditions compared to a $\mathrm{CHO}$-free placebo ${ }^{(2)}$. The aim of the present study was to evaluate the effects of rinsing a $\mathrm{CHO}$ solution in the mouth on cycle time trial performance in the heat.

Ten endurance trained male cyclists (Mean $\pm \mathrm{SD}$ Age $21 \pm 2 \mathrm{y}$; Height $179 \pm 5 \mathrm{~cm}$; Mass $73.9 \pm 5.5 \mathrm{~kg} ; \mathrm{VO}_{2} \mathrm{max} 65.1 \pm 5.3 \mathrm{~mL} / \mathrm{kg}$ / min) completed a simulated cycle time trial, undertaken in a climatic chamber maintained at $30^{\circ} \mathrm{C}$ and $60 \%$ relative humidity. Volunteers were instructed to perform as much work as possible in 60 minutes. Prior to the start of exercise, and every 10 minutes throughout, volunteers were given $100 \mathrm{ml}$ plain water to ingest, immediately followed by $25 \mathrm{~mL}$ of a solution to rinse around the mouth for 10 seconds, before expectorating it into a separate container held by an investigator. This solution contained either $6.4 \%$ glucose prepared in a sugar-free orange squash (CHO) or a taste-matched placebo (sweetener with orange squash; PLA). Power output (W), work done (kJ) and pedal cadence (rev/min) were recorded every 10 minutes, and at the end of the time trial. Heart rate, core temperature, RPE and perceived thermal stress were recorded at regular intervals.

Total work done during the experimental trials was not influenced by the solution rinsed (PLA $759 \pm 149 \mathrm{~kJ} ; \mathrm{CHO} 763 \pm 141 \mathrm{~kJ}$; $P=0.820)$. Mean power output was $232 \pm 42 \mathrm{~W}$ and $238 \pm 48 \mathrm{~W}$ during the PLA and CHO trials respectively $(P=0.526)$. CHO did not influence heart rate $(P=0.646)$ or core temperature $(P=0.712)$. RPE and thermal stress increased throughout both trials, with no differences between trials at any time point $(P>0.05)$.

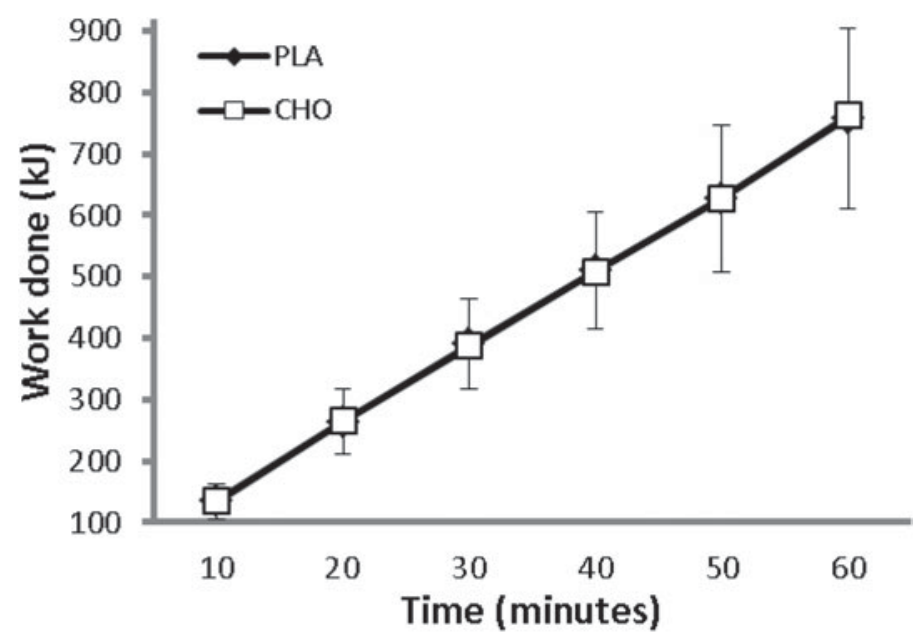

Fig. 1. Cumulative work done (in kJ) throughout the PLA and CHO trials.

In conclusion, rinsing the mouth with a CHO-containing solution before and during a cycle time trial in the heat, did not alter performance compared with a PLA rinse. While CHO receptors in the oral cavity appear to modulate central pathways associated with motivation during exercise in temperate conditions ${ }^{(2)}$, this response was not apparent when exercise was undertaken in a warm environment.

1. Watson P, Shirreffs SM \& Maughan RJ (2012) Med Sci Sports Exerc 44, 336-343.

2. Carter JM, Jeukendrup AE \& Jones DA (2004) Med Sci Sports Exerc 36, 2107-2111. 